\title{
Shifting Realities: An Interview
}

\author{
Barbara Sternberg with Barbara Godard
}

\section{Déplaçant les réalité(s)}

Dans cet entretien, la cinéaste Barbara Sternberg commente la production de son film Tending Towards the Horizontal (Tendant vers l'horizontale) qui inclue un texte de la poète acadienne France Daigle. Le film était tourné et editéd'abord. Daigleécrivait son texte à partir de la description du projet du film élaborée en vue d'une subvention. Ensuite, cependant, c'était impossible simplement d'ajouter une bande sonore aux images existantes comme prévu: Sternberg se trouvait obliger de refaire la montage, de réorganiser les images visuelles en fonction du texte verbal. Le projet de mettre ensemble un texte et des images entamait un processus de transformation où la bande sonore modifiait le rythme des images visuelles. Pourtant, il n'y a pas de convergence précise où l'image visuelle devient le référant du texte verbal. Il y a plutôt une convergence de processus et d'effet, c'est-à-dire le poème et les images cinématographiques sont ordonnés par la répétition et le film produit un effet calmant, la paix, tout comme l'image de l'oiseau produit pour Daigle en lisant son texte. Le film travaille plutôt sur l'espace entre images sonores et visuelles et leur modulation réciproque. Ce travail sur le texte differe des projets antérieurs de Sternberg qui emploie régulièrement des textes d'écrivaines modernistes telles Gertrude Stein et Virginia Woolf, superposant des extraits lus de leurs livres jusqu'à ce qu'ils deviennent flous ou que certains mots sont articulés en même temps par des voix différentes ce qui les met en relief, deux manières divergeantes de changer l'insistance. La conversation tourne alors sur l'emploi de la répétition, de l'importance de la répétition, pour le cinéma et la production en série du monde moderne, selon Stein, deux questions posées par Sternberg antèrieurement dans Opus 40. Stein présente la répétition et la succession comme des modes de distribution ou d'arrangement qui s'écartent de l'hiérarchie de la grammaire et du récit linéaire, de la "poésie patriarchale". Est-ce que cette langue de répétition est une langue filmique au féminin? Certes, elle est déployée par 
Marguerite Duras et Chantal Akerman. Pour Sternberg, c'est un langage visuel qui met en relief le travail du cinéma, sa matérialité-une suite d'images animées par l'appareil cinématographique. Bien qu'il est possible de cerner des images claires et distinctes avec cet appareillage, ceci $n^{\prime}$ est pas son projet. Elle s'intéresse surtout aux ombres, aux brouillages, aux transitions et superpositions, où une image se mue en une autre. Des questions du processus, de la perception, du changement de l'angle de vision qui produit des effets du réel différents.

B.G.: Tending Towards the Horizontal is a film that came out in 1988. In it you use a text by the Acadian poet France Daigle. How did this collaboration between you and France develop?

B.S.: I was living in the Maritimes when I met France. She interviewed me for a film publication out of the NFB in Moncton and then we kept up a friendship. I really admire her writing - it thrills me - there's so much there in so little - it's funny though because her work is French and I don't speak it. I get people to read to me and translate! At one point I remember her saying that if she were ever to do writing for film she would like to do something like I had done in Transitions, that is overlapping voices, recurring or repetitive phrases; she liked the use of voice in that and felt akin to it. It was years later that I mentioned I was working on this film and that I had images shot. I was thinking of continuing to separate the relationship between the voice and the image leaving each its own sphere and mode of reception - the visual and the verbal. (Usually I use sound effects, silence and voice, I don't use music per se, like a piece of music, to accompany or to work with a film because I sort of feel that's cheating.) So at that point it came up that we might be able to do something where France could be quite independent in her writing, do her own piece and I could continue working on the images. To keep separate the image and the text was a development of how I'd been working, creating a gap between the images and the word. I gave her the grant description. I didn't show her any images at all but in the grant description it mentions some key things-light and shadow and the idea of shadows and houses - I don't even think it gets into any more specifics about the images. Notions of construction and destruction and the home and the sky are mentioned - we agreed that she would write something and I would use it or not - that was the extent of the collaboration. She went away and wrote something and sent it to me complete, and then I decided to use it. It was up to me where the text would lie, but 
I didn't change the text at all.

B.G.:You've used aural texts by women writers a lot in your work. This, though, is somewhat different in that it's a living writer who's known to you as opposed to some of the great feminist modernists like Woolf and Stein. You've described this process as two separate things which came together in the construction of the film. What differences did this make in terms of the way you were thinking about the relationship between the visual image and the verbal text?

B.S.:Well I've always shot and edited the film first. It's almost that the film is complete and I'm satisfied with it and yet I have this impulse to add or work with language, as well as the sound of the voice (especially for instance in Transitions where there were these phrases and repeatings but a lot of it is the quality of two voices playing on each other), although I also want the information contained in the language. This is similar to what I do with images. I'm not wanting to totally abstract the image or paint on film or get rid of the photographicness, the identity of the image, and yet I don't want that to be totally where the content lies. We speak of the text of an image as distinct from or in addition to a simple statement of the subject. So I could also have filmed houses in a film about Toronto architecture! In Tending the houses are filmed such that reflection, shadows form the text: inner/outer. An image has its meaning, its referential meaning, but I also want it to operate on a non-intellectual and nonanalytical basis like a perceptive base.

B.G.: Perception is really important because that's the way you connect with the sound track in Transitions. The same text is repeated and repeated in various forms of displacement. Sometimes the different levels are all saying the same thing at the same time, sometimes one of the phrases comes a bit after another. This means that some words get focused on in an intense way and stick out so that you hear them in a different relationship and their meaning shifts. Is that the way you see the visual image working? Is it a mode similar to using an image that has some form of referential content which you haven't completely evacuated? You are interested in the abstractions of shadows and light, blurred and clear perceptions and things like that. Is layering the sort of thing that you're trying to do with the image too?

B.S.: Yes exactly, especially in Transitions it was the most obvious because the image was physically layered and so was the voice, so there were many images in one frame and then some of those images that were together in one frame came back but in a different set of relationships. 
You can't leave it as saying - oh well this meant this and that leads the plot forward and now I know what that is so I don't have to see it again cause it just keeps the same - diminishing its effectiveness in terms of just meaning. In Tending Towards the Horizontal there are various birds flying and they come in and at a certain point one just senses whatever it is in birds flapping, I mean there's no "meaning" - you're not necessarily trying to "say" that the bird symbolizes such and such for this film, nor is it that this is the story about a bird who's en route to some specific place. In Tending the layering is not literal or physical - an image can have several even contradictory meanings simultaneously, but more, it can be experienced in different ways: as meaning and as bodily experience or sensed - different levels of consciousness are all activated. In Tending I was trying to have images as affective agents, more than use them as symbol or representation. In Transitions, with the layering, the sound and the image are doing parallel things. It's a similar technique throughout the image and the treatment of the voice. Whereas I had thought in each of the films after that, as I said, that I was starting to not have the image and sound be in such a supportive and parallel relationship and I had thought that by the time I got to Tending I was going to have the image be more the perceptual, experiential, rhythmic line and leave to the words the analytic line and in that way divide the two experiences. So you would be listening to the text or the voice with a certain part of your mind and way of getting meaning and you would experience the images another way and they would just sit there together. But in fact, when France sent me her text, because she writes in such a suggestive, metaphoric and imagistic way, she did with language what I was doing with image, I think, and so my plan really didn't hold up. I think in a sense the words and the images are working in a similar way although not simply being one to one with each other. When I was editing I did have to bring them together. I had to take the two into account for rhythm, the length of her sentences, the speed of her voice, where pauses were and the image, the rhythm of the images - they had to work together, you can't just ignore that.

B.G.: So the editing in this way is the selection, the choosing in/as composition...

B.S.: Yes and where to make spaces and pauses.

B.G.: ... and works to intensify certain things.

B.S.: Yes, where there's a silence an image may be more evident or where a word has a correspondence or an unusual incongruity. Moving 
the sound one way or another really changes what is seen. Something jumps out or is barely noticed. I had to choose one placement finally so lost some possibilities, then got others. I actually could have edited it in a more satisfying way. It's very easy to tell when you feel satisfied, when something just lands right on, like the rhythms come right together or the images and words - you say the word bird in the text and you see a bird and you go aah and it feels right - so often I could find those points and then I moved it off. I sort of wanted to create this space. Sometimes I let them come close because you want some sort of moments of rest where there's a pause and some satisfaction, but I tried mostly to have them refer to each other or echo each other. Mostly I tried to keep those very direct correlations away from each other so that each one of them would have their own existence. I wasn't illustrating bird because she said bird nor was she talking about bird because she saw an image of a bird - they weren't simply supportive of each other in that way. That doesn't interest me - to illustrate.

B.G.: Certainly that was very clear in terms of the effect of the text. They weren't overlapping so that you didn't have the text providing a linguistic referent for the image. Where I felt a convergence was in the emotional effect. In one of the letters about the process of writing the poem that France writes to you, she talks about how this image of the bird is haunting her and it seems to have a very calming effect and that was the emotional effect of looking at the total composition. When one came to the end, there was a feeling of great calmness, great serenity. There's a synchronicity there that reinforces the impact.

B.S.: Just to clarify something first: the letters in the text are a part of the text as France wrote it, not inserted. I think there is a sensibility and approach to the world, an observational stance that perhaps connects us. But also the effect of the work is its totality and this film in particular is not so susceptible to a parsing and a summing up, but needs experiencing as a continuity. It moves along with a sameness.

B.G.: Looking at her earlier books, one has the title - Film d'amour et de dépendence - - it's about the whole process of trying to make a film about a relationship where there's a film that's being made and a relationship in conflict within that. She has been thinking very much about film in a somewhat analytical way and writing about this at various points prior to your working together. She describes the ways in which, once the camera gets ready and turning, and you've got all the technicians around and focus on the field of the image, then reality gets all 
scrambled, all mixed up. Somebody's digging — the idea of digging and digging and using images in this way in the whole cinematic process of getting beyond the perceptible into a construction of something new the construction workers who are throughout "Tending" too - the importance of the idea of construction through the process of film that she's talking about. The other thing she also says is that she relates to things. She talks about distance, unbridgeable distance and of the unknown. Everything is good for cinema and for writing. She's trying to think through parallels between the two, between visual and verbal images. The other precedent one could see in these books is the way they were structured as books of poetry. They were constructed on a double margin on the page, laid out like a film script where you have not the image and the verbal text in two columns but two different kinds of textual systems and of notation facing each other. In the line on the film, you've got a meditative prose poem and on the other side of the page you have dialogue - something that's set up as dialogue. You have this moving constantly, structuring the book. So there's a way in which she's thinking or she's constructing her book in terms of the double processes and layerings that produce different effects. Has she done actual work with film?

B.S.: My film is the only one I think that has come to fruition. When she was writing this for me she actually was working on a film script which the NFB was to make with Lea Pool as director. But that never came into being as far as I know.

B.G.: But in terms of the way of writing out a film script - it reads that way - the double columns, two systems of signification. The other thing about these books is that they have a really strong image of the house throughout. In the first one, Histoire de la maison qui brûle the house is an old story about Acadia and there's a sort of legendary quality to it. It's something that happened in the community and there's an attempt to make the house some form of symbol for Acadian identity. That disappears in some of the other books but it is an image that continued into the poem for Tending Toward the Horizontal which is really a double image of movement, of peregrination. There's the bird's movement, where there is constant seeking to return, there's the house sitting on the hill — the tension between those two kinds of images, the two kinds of movement, two kinds of relationships with the space they set up.

B.S.: I wonder if there's a parallel to this in the alternation in the images of all the panning past motion and the segments of slides. Even 
when the images are the same there's a different impact - the constant motion, not inside, not 'at home' and the stillness of the slides, but with their atemporality, the nostalgic or deathly nature of a photograph. Also the inference of verticality in 'tending towards' the horizontal was important, and I did use some vertical camera moves, tilts up and down. It's interesting how closely our works parallel each other when we analyse it now, and yet there wasn't any of this pre-thought on France's is and my part. For me, putting her "letter" about poetry over images of partial buildings (being constructed and torn down) and the earlier bricks/writing association felt good - also the blind woman's hand groping along the wall - the meaning behind the words, unseen. Also for me, film is a construct and yet it's intimate connection with reality perception - has always been a motif. Stan Brakhage commented to me once that for him the effect of my layering of image and sound (in Transitions) was to "interupt the drama and let reality through." Also, I've had this notion of house/societal framework prominent in other films. Though in Tending, house has broader and vaguer significance. A film preceding this one that I had done called A Trilogy uses letters that my son and I had written to each other (and then eventually the film just has letters of the alphabet, that's kind of starting again and being free to construct or to create out of just letters) actual letters written - Dear Arlen, Dear Mom - this kind of thing - and France had seen that and we had talked a little bit about different voices she has in her book, perhaps, in the two sides of the page. In film, the different film styles are voices perhaps. In Trilogy there were segments that, in filmic styles and the kind of text I use, are quite different from each other and I hoped would set up for the audience different ways of experiencing the film. I had three texts: the first was historical statements (what we like to call historical "fact" and we put it in the form of statement to make it seem actual), the second was in story form, an initiation rite and then the third type of writing was a series of questions. The filmic styles referred to different codes of meaning - the meaning from how the image is shot, not what the image is about. The first segment was a long take which, according to Bazin's theory, that's the most believable - don't cut it up. Just let us believe it because we can see it happens in real time and real space. So the first segment of the film is this one long running and in that is also repetition.

B.G.: All of the movement along the trees as the person keeps running and all of the trees are the same, though not quite the same trees. 
B.S.: There is again that horizontal movement which I pick up in Tending Towards the Horizontal where the camera is always going past something so we never sit still with it.

B.G.: The movement of the moving image is really emphasized in that way. The camera never stops moving, a sort of "making strange" that draws attention to the processes of perception.

B.S.: The second section was supposed to be cut like television or hollywood movies - - the typical continuity cutting of narrative storytelling - and takes place in a kitchen - within the house, the social structure, and daily life. And then the third section was the mystery. It's in the daily life that the mystery of life is - not taking some boat over a mountain, à la Herzog.

B.G.: Yes, but there are evocations of that because where that third section is shot has been...

B.S.: Silbery Hill which is a neolithic fertility mound, the pregnant earth - a site of mystery and ritual. This third section is again layered images and so the shooting style is the least realistic — of what we've learned as audience to take as realism. But the third section for me is the most realistic in the sense of how we really experience life - which includes our apprehension of the mythic and a spiritual dimension the overlapping, the coming back on something that sort of repeats in another way, like the child runs and falls and then we see him later. Repetition also gives a sense of ritual to an action.

B.G.: And the falling is repeated several times so that the image recurs in different combinations.

B.S.: And I think that's how our minds work. We don't experience things in a straight line trajectory - they come back on us, we imagine them before they happen, we remember them after they've happened, we relate them to each other in different circumstances. It's sort of like setting out, in a way, how we perceive the world and how our minds construct it.

B.G.: The third section then comes as a critique of the notion of filmic reality, therefore, of the filmic connection with reality.

B.S.: Exactly. The audience is moved in and out of being connected with it and then being put back into their own heads or their own selves (via the three texts and changing film styles) to think about what's going on. The audience's positioning of how it can receive the film shifts and for some people that's bothersome. They just want to be moved the whole time. But the last section I think actually catches hold of people. 
B.G.: The emotional interconnections are immensely strong there because of the play of memory and the fleeting connection with images to various things that impinge on the viewer in different ways and they pull up different sorts of half-remembered things, so that there's a different kind of interaction. It's not that there's no emotional potential, no affect in terms of the connection with the image, but that it does work in different ways - more teasing - half sensed, half felt.

B.S.: The way I work with images does not count on people necessarily having a certain association with that image. Some of the images will have more of a connection or a symbolic reference, a shared meaning for everyone and some are just my things, like bugs or waves. But they have a movement in there and because they're fleeting and they come back there is an accumulation within the film. Sometimes they're in there so briefly that you don't even know what you see necessarily.

B.G.: I certainly haven't with a lot of the things that are playing in the shadows in Tending Towards the Horizontal. That is because you get the effect of light and shade, light and dark as almost abstract patterns but not quite and you're not sure what you're seeing, whether they're leaves filtering something. There are a number of shots that are images of the sky where you've got the sun being blocked out and the different patterns the clouds create with different colours. Those are quite different because the whole play of light - it's not quite like the Monet paintings where he does the cathedral five different times a day to map the effect of shifting light on perception - but you do move through time there, where the image is of the same object or the same house or the same landscape shot different times of the day and year. But the play of the setting sun and the effect that gives in transforming the quality of the gold comes down in the end to the one image, a really strong one, that draws them together where you've the blotch of sky that's orange behind - the setting sun - this dark house silhouetted against it with the light in the window. It's light from inside of the house that's generating the colour, it's not a reflection though some of the shots are the reflection of the sun casting its glow over the buildings and the trees.

B.S.: It is the bringing together, not of the oppositional nature of those things - like sunset and sunrise are the same colour. There's construction and destruction, buildings in the process of being built but also in the process of being torn down and I think sometimes you're not sure whether the house is coming down or going up, each contains the other.

B.G.: Exactly because all the workmen were there and yet the images 


\section{$52 \cdot$ Tessera}

are really unclear at times. When you see a half structure and something protruding, it was uncertain whether the parts that were hanging out were unravelled because something had been ripped out of it or whether they were neat because somebody was putting it up and the next part hadn't gone up. But there were also other things that came into the images there too. In France's poetry there were various kinds of paradises or images coming from biblical tradition, various kinds of havens, like Jerusalem the golden, and the fact that you had all these houses with the gold light of the sun on them evoking that paradise but at the same time there was also a consideration of homelessness. There were images that came out of the war, out of Europe, the holocaust people being moved. It wasn't clear. There seemed to be people in migration, notions of exile, of the city where people didn't feel at home.

B.S.: I think that comes often because there is this movement so that there was never any "in place," there was never any moment of just holding on to something and of having it belonging to you or you belonging there. So that this always moving did that. But also the relation between inside/outside is brought into question with the reflections of gold light in the windows and the orangeish indoor light. I used some images of buildings in high contrast (that made buildings look black and white) and the text was saying something about the Jewish cemeteries. At first I worried about certain associations with the holocaust, and then I thought well no - let it have that because now the image looked like smoke rising from a crematorium to me, but it wasn't. All those houses were in Toronto except a few of the wooden structures from the Maritimes, from a different sense of home. But I think also the people walking along the beach in that golden light, a child and a parent - they just somehow evoke, although they're not anybody, this sort of passage and this being in-between and this sense of betweeness or something. But trying to stress the "and," not the polarities between these things. I think if anything for me this kind of calm or suspension, dusk and dawn, the light at the moment of change - but filmed as a moment of suspension. There's another section where body parts are rolling on each other and come in and out of dark and light, actually in and out of the orange emulsion which connects them with the 'inner' orange light in windows. I wanted two bodies intertwined but I didn't want you to be able to tell necessarily if it was a man or a woman but anyway two. And it's interesting because again this is a point that we hadn't discussed but the text talks about a figure on the hill and questions the man or womaness of it. 
This is another point, in language she has the word "a figure" whereas in film I have to film a man or a woman so I work with shadow or certain body types or with a certain distance so that you can abstract things.

B.G.: Part of it concerns perception, because you're playing with the clarity of perception, blurring things and so putting the work of making distinctions back on the viewer. As you say, people will read onto those two bodies - if you can manage to make them appear as neutral or gender-indiscriminate bodies - very different things.

B.S.: There's some places in my films where I really wanted it to be a woman for instance, like at the end of Trilogy it's a woman that dives into the water and that was important to me that it be a woman, but there's a lot of places where I want it to be human being or figure. It was very interesting - to the extent that we worked separately - how certain things came together.

B.G: In putting the two texts together, when you speak about this you emphasize this constant movement, that it's the camera moving along from one image to another. It never stops moving and has an estrangement effect that operates to break down the habitual norms of perception and identification in order to produce knowledge about relations of production. This continuous movement collapses the spectatorial position of detached observation, of voyeurism with the look as appropriation. There are these moments of pause in the midst but what happens in the pause, and it's the only thing that stays still in the succession of shots, is where you move into - well it's not blank in this case - but where your images move and seem to stop and you have a bit of white, but the white isn't a pure white, so it's as though the screen goes blank but it doesn't. You can see things coming through or there are some points where it's darker or there's a bit of blue at one point that stays on screen so that there's a pure colour that moves across the screen at various times to punctuate the phases of the movement. You've used the poem in that way too, and it breaks up the sense of there being a referential convergence, that is, that the poem is an application of the images, or the visual images an application of the poem. The way we have to look at them is as implication, in terms of their intersection, the point between where they interact. The poem is used and it's repeated many times throughout, but there are also places where there's silence in the sound-track so that you will have the poem being read and then there will be points where there isn't any voice and there is just the visual track. This refusal of synchronicity, of marrying a voice to a body in a fiction of presence, 


\section{Tessera}

figures a certain negativity. One of the other related things I noticed about this use of sound and sight was that the title of the film and your credits were given in the visual images on screen and then the poetic credits were given orally. They were included as a line that was spoken, not written graphically, so that the idea of these being two separate systems was very much drawn to our attention. How did you make the decision about where to put the silences in the poem, in the sound- track, because that was your manipulation of the poem?

B.S.: I had the film edited already before I got France's text and then when I tried to play them together, just transfer hers to tape and run them as is, it didn't work. So I had to re-edit the whole film and what happened was really giving more space to each. The text has sections - there's the three images: the bird, the woman in the library and the man / figure and then a refrain and I kept the sections more or less intact - stretching pauses. And made longer pauses as the images required between sections. I played sections of text over different segments of images and saw / felt which worked best with which - rhythm-wise and association-wise (or lack of). I was constrained by keeping the order of the texts and had to make compromises. I watched where the text would create a meaning for the image or limit possibilities. It was a hard balancing act. Interestingly, the voice seems to work with the image better as we go along in the film. At first there's a pull between them maybe and then the voice and rhythms mesh... I laid the sound in and listened to it and adjusted things and then tried to give the film its time. Also, when I thought it was either introducing a different kind of movement or another filmic idea or image idea I might delay the sound. What happened generally was that the sound segments were closer together at the beginning and the silences were greater towards the end so it spread itself out more. You could follow the text and pay attention to the text more easily at the beginning because I think generally when there's something to listen to people hold on to that, they pay attention to that and they follow it and so the film was more background at the beginning. I used long passages of similar imagery with few changes in it or little flicks of change that would catch the eye. Also foreshadowings. Then the silences increase but at the same time the images are varied and some are more of those kind of pure colour or abstraction, more and more shadow and light and less and less a thing, an object that was filmed, a representation. The film moved towards silence and towards light and dark, sort of a more abstract place. When the sound-track came back in, it was like 
you had been in a silent film, you were just with the images, and then the voice came in and sort of woke you again to another world or part of yourself or part of the film. Light and time are two basics of film and it's wonderful to be able to work with a medium that, in its very nature, is already dealing with these issues of how we are in the world. Film naturally has two colours that it goes towards - it's either balanced for daylight or for tungsten. Daylight is a bluer light and tungsten indoor light, is an orange light. So when I was going to those pure or imageless frames of colour it wasn't totally arbitrary. Ilet film go to itself, reveal its own emulsion, and images emerge from and disappear into the emulsion.

B.G.: So you were accentuating in that way its material medium and the traces of the image's transformation as conscious manipulation of signifiers.

B.S.: Yes its materiality and its direct parallel to our experience of light. Also there is a sameness or a comparability established between diverse things: flickering light and sprays of water share a rhythm; orange triangles of sunlight and triangular rooftops; intertwining flesh-toned tree branches and bodies rolling in and out of the orange film emulsion; a body rotating and light flickering. A transmutability through movement, colour, rhythm. The rhythm of this film, as you were saying, the kind of effect of calmness, the effect that France's text and the film had was similar even if the exact images weren't because this film was edited quite evenly in a way and I think in our normal sense of things that can feel boring. People expect highs and big disruptions - climaxes. This film does get calmer some places or comes to a bit of a rest in clearness or in silence. But it sort of just keeps going on and on and in a way, for me, that's how life is, it just keeps going on and on and on and on everyday you know the sun rises.

B.G.: Well that's one of the important things again when talking about this, the sense of the medium and examining the possibilities of the medium, which I want to talk about in a second. A constant concern in your films has been with questions of filmic possibilities and different kinds of perception and attention. However your films have often been read in a landscape tradition, that is, referentially. One of the questions that I had relates to what I perceive as your refusal of referentiality through the heterogeneity of voices and images. Moreover, the letters France incorporated with the poems were very self-reflexive: they were about the process of writing and about questions of reading and there is, 
of course, that image of the woman with the book, the woman in the library with the book, so the whole verbal foregrounding of reading and the self-reflexive element of textuality. Has this in any way helped shift ways of viewing your work so that people are able to see more in this film, Tending Towards the Horizontal, the fact of your concern with the medium of film and with the process of transformation of images?

B.S.: I don't know because Tending Towards the Horizontal sort of came and went. There hasn't been anything written on it so I don't know what effect it's had. I think for me each film refers to the previous one. I move somewhere on a conscious level at some point but then I almost forget it and different aspects of the film take over - a process of forgetting, of awareness and sinking below the surface. The interest with the medium itself is always there in some way - an interest in the material itself combined with social issues or ideas and also interest in the medium as communicative tool with its conventions. The first film I showed, Opus 40 for instance, it starts out as if it's a documentary - that play between that sense of reality and film - then this thing starts repeating on itself, the screen splits, the sound track moves from being the actual sound in a foundry to being the sound of the projector. Also, how I treat the image - that sort of reality principle because of its photographicness and yet abstraction or repetition or layering to move it beyond that or free the image to some extent. And working with manyness - relating many images in an accumulative effect. And the relationship between the sound track or the voice and the image - I've been moving them farther apart until in the last film, I used sync sound. I put the voice in the mouth and there it was and no sound over the rest of the film - the images were free to be received that way without this other engagement. I took it as far as I could go, this gap, until just a complete split: sync sound and silence. But in terms of the way the films have been looked at, I think, because they're experimental films they haven't been looked at really at all. The art world doesn't - I don't want to make this sound like a complaint but I think it's the reality of it - people writing on the other visual arts, don't address themselves to it. In terms of literature, there could be a parallel to feminist writing, and lesbian - new forms breaking open, margins, of the body - we could be looking at my films, the movements, rhythms, and subjects from notions of the body too, I think. So I only can say what its effect is on me because I seem to be the only one who'll take these films seriously! - no, I shouldn't say that, but you know what I mean. 
B.G.: I do. I see these quite enormous resonances for me and the sorts of things that I thought about trying to do with film a long long time ago in terms of the concern with time and with perception and the exploration of the everyday and about the questions of, well my particular concern was with memory. What is constant in a lot of your films that might draw attention to this question of the interrogation of the medium or self-reflexivity is the concern with repetition. There's a way of drawing attention to things. Sometimes the obsessive repetitiveness draws attention to itself with the constant movement, the fact that there's never a pausing. Now this is one of the things that you've played with enormously in terms of the use of the poem by making the poem repeat itself over and over again. The other thing is that the poem within itself, in its refrain, is concerned very much with this question of repetition. This is interesting, too, because there's the betweeness that you've been talking about, between the language and the image. This is the question of the French line that comes over and over again, "Vingt fois sur le métier remettiez votre ouvrage" which has been changed to "cent fois" and "remettras." I've dug around and found that it's a quotation from Boileau's L'Art Poétique I, 172-3 [1674] which is the neo-classical treatise on poetry, how to write perfect verse respecting all of the unities. There is an interesting shift that happens, because the way Boileau continues, the second line is about polishing and re-polishing the work in order to go over and over it until you get something that's an absolutely perfect object. When I went to check it out in the dictionary of proverbs, I found it not under métier where Ilooked for it, which had to do with work, the quality of work and the quality of craftmanship and the attention to process, but $I$ found it under the artist. The way it's been used, the changes that have been made by France, draw attention to the question of repetition. I wondered where this interest in repetition developed for you.

B.S.: Actually, I came to film from photography. I kept making series or printing the same image over and over with changes. In experimental film, there is a history of "looping" film, refilming the same footage over and over - so then you get the identical footage taken out of its context and now having a relationship with itself. That was done quite a bit in experimental film but although things repeat in my films I've never set up a loop where it's simply the exact same thing. In Opus 40 for instance, there was the work (men in the foundry going through a repeated sequence of motions) and the physical nature of the surroundings (rows 
of work stations, window after window) and the everyday over and overness which was in the situation. I was interested in repetition in habit, in ritual, in identity. By repeating images you can abstract them, or generalize beyond the specifics of the scene they're shot in. As for the film itself, I was very aware that filming is a repetitive process. The cartridges in super eight are three minutes long. So every three minutes there would be this changeover. I made a matte so I would wind the film back and film over the same amount of footage again. There is the 24 frames per second which allows film to exist at all in its capturing of the image and in its re-projection of the image. So there's this intermittent, single, repetitive motion and the sound of it - the camera clicking and the projector clicking. Well, all of life obviously involves repetition - it's a structuring principle. Leila Sujir suggested to me that in A Trilogy repetition is a storytelling principle - not the linear storytelling that we've become familiar with, a cause and effect kind of thing, but closer to how we experience our living. A way of ordering the world in cycles and in circles, and in that sense a symbol. In Opus 40, I use voice-over from The Making of Americans by Gertrude Stein in which she writes about the whole building up of our knowing of ourselves and our knowing of the world through this constant repeating which she said can become deadening if we don't pay attention to it and see the slight variations within it. The way we put ourselves out as human beings is through this repeating of ourselves in being who we are and all of history is a repeating and coming to know repeating and loving it! And of course her style, I mean, there is form and content, or form as content, because whether you're listening to what the words are saying or not, she's doing it. She starts sentences again with the same phrase and she builds up small units and then there is this wholeness and this unity through the repetition of these small units and that's exactly what film is. You have a sense of a shot even though you have 24 discrete separate little frames because the extent to which they're different makes the motion but the extent to which they're the same makes continuity. And on a larger scale, building up the sense of a film from many shots or images till it is a "being" is what I was trying to do in Tending and in a later film through a relation (rhythmical) of even smaller units of several frames.

B.G.: The connection with Stein is something that's really meaningful for me at the moment because I've been reading a lot of Stein lately. In her lecture manifesto, Portraits and Repetition, which is an attempt to explain questions of composition and gender, she talks about these in her theo- 
ries of composition, ways of distribution or relation - "conjugation" for which succession and intensity are two major things she's concerned with. She talks about the question of change and the relationship of change and generation. One of the interesting things she says,

In the beginning and I will read you some portraits to show you this I continued to do what I was doing in The Making of Americans, I was doing what cinema was doing, I was making a continuous succession of the statement of what that person was until I had not many things but one thing. As I read you some of the portraits of that period you will see what I mean.

I of course did not think of it in terms of the cinema, in fact I doubt whether at that time I had ever seen a cinema but, and I cannot repeat this too often any one is of one's period and this our period was undoubtedly the period of the cinema and series production. And each of us in our own way are bound to express what the world in which we are living is doing. (Stein 106)

B.S.: That's wonderful! I knew I loved Gertrude Stein!

B.G.: When you were talking about Opus 40, the thing that I thought about is the assembly line, series production, the whole rise of the factory and industrialization and the cinema as a mode of artistic representation which atomizes and sequences or puts in a succession and produces something at the end that's an effect from a whole series of discrete elements.

B.S.: It was Opus 40 because it was the 40 hour work week and opus meaning music because that's the other influence.

B.G.: But there are some other pertinent things that Stein is drawing attention to there in the parallel between her writing and the cinematic process, key to her work. Cinema offered her a methodological solution to her portraits: "By a continuously moving picture of any one there is no memory of any other thing and there is that thing existing, it is in a way if you like one portrait of anything not a number of them" (Stein 105). She develops numerous perspectives on a thing, keeping it always in movement through shifting angles of vision. Stein talks about the fact that series is differentiation rather than synchronicity or resemblance: "In Composition as Explanation I said nothing changes from generation to generation except the composition in which we live and the composition in which we live makes the art which we see and hear." So composition - ordering and distributing which make our perceptions for us - is 
writing as writing rather than writing what one intended to write, not something for which one has had a previous idea, but writing as research - the whole question of movement into the not-yet spoken. "The strange thing about the realization of existence is like a train moving there is no real realization of it moving if it does not move against something and so that is what a generation does it shows that through differentiation," through the point when one thing shifts into something else. One thing seen always in its relation to other things.

B.S.: Wow again. The relation to film, motion picture - the illusion of motion from a succession of still images because of sameness with some difference. Germaine Dulac developed a theory of film based on the transformative possibility of movement. Also "generation" is a filmic term too. When one refilms from original film or prints from a print the print is the next generation - the image changes slightly.

B.G.: Stein demonstrates this differentiation through incrementation in her portraits which, as she emphasizes, are different from description. "I say portraits and not description and I will gradually explain why. Then also there is the important question of repetition and is there any such thing. Is there repetition or is there insistence. I am inclined to believe that there is no such thing as repetition" (Stein 100). The detective story, a formulaic genre, demonstrates repetition as difference. Though the crime or theme and scene is the same, "that is, if you like, repetition, that is if you like the repeating that is the same thing, but once started expressing this thing, is insistence, and if you insist you must each time use emphasis and if you use emphasis it is not possible while anybody is alive that they should use exactly the same emphasis. And so let us think seriously of the difference between repetition and insistence. Anybody can be interested in a story of a crime because no matter how often the witnesses tell the same story the insistence is different" (Stein 100). Insistence is a question of emphasis, that is, of selection and ordering or relation which is, in turn, a question of perspective or angle of vision. Elsewhere, in The Geographical History of America, Stein expands on shifts in perspective as these implicate gender in changing the emphasis or insistence or composition of a portrait. The "only real literary thinking has been done by a woman" in the present era, because that "woman related not to an historical tradition but to a particular way of seeing." For Stein, composition is not a question of resemblance or of remembrance, that is of sameness, but one of rhythm or movement, that is of making distinction. Repetition is something you use extensively in your films. What is its importance for you? 
B.S.: Repetition patterns and creates rhythm. We each have our own inner rhythm - it's basic - in our walk, in intonations of speech, in our bodies like rocking, swaying. And in my films, I edit to that (the rhythm, not informational concerns, determine where to cut), and it's there in what I shoot (the motion, rhythm of waves lapping, light flicking), and how I shoot it (camera motion). In this sense of repetition as rhythmic and in us, I think of Virginia Woolf. I've been wondering if rhythm in film could be identified as culturally or gender-linked. It's obvious in speech patterns and in writing; like in Lillian Allen's use of West Indian dialect and rhythmic line and Allen Ginsberg's dovening or hebrew chant-like repetitive rhythms. Is my editing rhythm female? Canadian? Jewish?

B.G.: We were talking earlier about the seeming sameness of the repeated image which may appear monotonous. I am thinking of the response that people have to Marguerite Duras' India Song where images are repeated continually. The people I saw it with couldn't bear the film and kept begging to leave: I could have watched it over and over again. Is this a gendered filmic language?

B.S.: Or Chantal Akerman's Jeanne Dielman which deals with the everyday, in its detail and its repetitiveness. The reaction of people coming out of the cinema was hysterical. Lots hated it, it made them restless. Duras' name is omitted from publicity for the film of her novel L'Amant (The Lover). I haven't seen it yet.

B.G.: She did scripts for Alain Resnais that explore questions of time through repetition, especially Hiroshima mon amour where the heavy weight of memory and sensuality are conveyed through repeated frames of moving sand. But she has totally repudiated Jacques Anand's film of her novel.

B.S.: It's easy to see how the novel could be turned into a steamy sex thing...

B.G.: Exactly what happened, there's a focus on bodies and action, not Duras' typical attentiveness to surfaces and perception.

B.S.: Feminine, masculine, differences between Being and Doing, as Rae Davis" title puts it. Different stances, it suggests, "we do and make things happen," or "we are," just being. Mind you, her title has "and" -

B.G.: Stein questions this kind of opposition, writing for writing or writing as research, focusing on processes in/ of reality, important terms for her that she takes up from Whitehead, one of the geniuses with whom she connects herself. Post-Einsteinian relativity: the observer is part of the creation of reality. In the act of observing you've altered reality. Changing the angle of perspective brings into being a different reality. 
B.S. We observe and in observing we shape. That's what cinema does well, shifting the angle of vision as the camera moves around an object, getting at different angles of it which a still photo can't get at. Nor can theatre which is limited by the perspective of the stage so that one can't see behind or down on or up on an object or for that matter before and after. In film you can bring all of these different angles of vision or perspective together, spread over time. And of course, the reality is shaped in this constructing.

B.G. Your concern with the in-between, with transitions, incremental shifts.

B.S. Between, yes, between sharp distinctions, between here and there, now and then, light and dark, shifting realities, modes of perception, constructs of mind/film, changing sameness, similarities in the diverse. You can shoot something very clear and distinct, still. But I'm always moving past it... I think the in-between transitional space is movement. There is a constant movement between revealing and concealing. These are the processes of the world and we are in this process. It is this process that interests me. Not one state or the other.

B.G. When we print this conversation, then, we won't reproduce any of the visual images from the film because that would fix and freeze the movement, the "tending towards" into a clear image instead of the blurring movement of the camera, the static quality of the page arresting its possibilities for transformation.

B.S.: I realize now (after all this talking!) that what I try to do with images is what words can so easily do; namely express something that doesn't exist physically - much harder to do with a photographic medium. In words one can say, for example, "to skim across the water, to skim across the days, to skim across all things..." (Dyana Werden). How to express this idea, feeling in film? Also, we didn't directly discuss the motivating ideas behind the film (although the title alludes to this as does mention of manyness and transmutability, and non-oppositional): a view of the world that has to do with oneness - the light and the shadows part of the same; or bigness, a sense of beyond me, excess and the pleasure/pain of that - in a word, something of the sublime. 
Shifting Realities: An Interview · 63

\section{Works Cited}

Bazin, André. What is Cinema. Berkley: U of California, 1971.

Davis, Rae. Being and Doing, Rae Davis: Work (1959 - 86). London:

London Regional Art Gallery. 1986.

Dulac, Germaine. "Du sentiment à la ligne" in Films as Form: Experiment in Film 1910 - 1975. London: Hayward Gallery, 1979.

Stein, Gertrude. "Portraits and Repetition" in Gertrude Stein: Look at Me Now and Here I Am, Ed. Patricia Meyerowitz. Harmondsworth: Penguin, 1967. 